\title{
Kinetic Stability and Rheology of Water-in-Crude Oil Emulsion Stabilized by Cocamide at Different Water Volume Fractions
}

\author{
Rasha Mohammed Abd, Abdurhman Hamid Nour, and Ahmad Ziad Sulaiman
}

\begin{abstract}
The formation of water-in-crude oil encountered in many stages such drilling, transporting, and processing of crude oil. To enhance and control these processes, it is necessary to understand the emulsion mechanisms. The present study aims to investigate the stability and the rheology of the crude oil emulsion stabilized by Cocamide DEA. Two types of Malaysian crude oil namely; heavy crude oil, and light-heavy blended crude oil (40-60) vol. \% were Physio-chemically characterized, and fractionated by the SARA method of analysis. The stability of the emulsion was investigated using $(0.2,0.5,1$, and 1.5$)$ vol. $\%$ of Cocamide DEA at different water volume fractions $(\mathbf{5 0}$, and 20$) \%$. Rheology studies were performed to demonstrate the effect of apparent dynamic viscosity on the emulsion stability. The dynamic viscosity was determined by Brokfeild Rotational Digital Viscometer. A wide range of temperatures (from 30 to 90) ?C, and shear rate (from 17 to 85) $1 /$ s were covered. Results showed that higher concentration of Cocamide DEA and lower water volume fraction of $20 \%$ were effective in stabilizing the w/o emulsion at room temperature. In addition, the stabilized emulsion showed a non-Newtonian shear thinning "pseudo-plastic" behavior.
\end{abstract}

Index Terms - W/O emulsion, cocamide surfactant, stability, rheology properties.

\section{INTRODUCTION}

Emulsions have long been of great practical interest due to their widespread occurrence in everyday life. It is a fine dispersion of water-in-oil or oil-in-water with drop sizes usually in the micron range [1]-[3]. It has the ability to resist changes in its properties over time, the more stable the emulsion, the more slowly its properties changes [4].

In the petroleum industry, the methods of emulsion and blending with lighter crude oil have been used as a common methods to transport the heavy crude oil through reducing the viscosity, as the conventional pipelining by heating from the reservoir to the refinery is not a proper approach due to some drawbacks associated in term of operation cost [5]. However, there are several obstacles with the emulsion approach in term of the selection and the cost of surfactant, efficiency of surfactant in stabilizing the emulsion during transportation and separation once the destination point is reached [6].

Another difficulty related to emulsions, their formation is costly in term of chemical used, production losses, as well as

Manuscript received October 9, 2013; revised December 4, 2013. This work was supported by the University Malaysia Pahang with the Research Grant "GRS 120319", and Pertronas for donating the crude oil.

The authors are with the Chemical Engineering Program, Faculty of Chemical Engineering \& Natural Resources, Universiti Malaysia Pahang, Pahang, Malaysia (e-mail: rashaam12@gmail.com, nour2000_99@yahoo.com, ziad@ump.edu.my). an environmental problem in case of oil-spillage [7], [8].

During the preparation of the emulsion system, a surfactant is usually added into the oil-aqueous solution as an emulsifying agent to accomplish two functions; to lower the oil-aqueous solution interfacial tension, and to stabilize the presence of the oil droplet phase within the aqueous continuous face to avoid the oil droplet coalescence mechanism [9], [10]. Cocamide DEA or Cocamide diethanolamine, is a non-ionic, biodegradable, and low in toxicity surfactant made by mixing the fatty acids from coconut oils with diethanolamine. It is a viscous liquid (450-850) $\mathrm{m} \cdot$ Pas that has a molecular weight (280-290) with HLB of 13.5. It used as a foaming agent in cosmetics products like shampoos and hand soaps as an emulsifying agent.

As the new trend in the research work exploration for environmental friendlier compounds and materials are associated by the inspiration of introducing new approaches and materials for saving resources. The present study was performed to investigate the kinetic stability of the water-in-crude oil emulsions stabilized by the natural surfactant Cocamide DEA which is the first part of an experimental study to demulsify the crude oil emulsions by microwave heating technology. The main point of this investigation is to characterize the crude oil samples, examine the stability, and to find out the rheology properties to understand the flow-ability behavior of water-in-crude oil emulsion stabilized by Cocamide DEA.

\section{MATERAL AND METHODS}

\section{A. Crude Oil}

In this study, two types of crude oil samples were collected from Petronas Refinery at Melaka, Malaysia for investigation. The oil samples were marked as crude oil A and crude oil B (Heavy - light blended crude oil at 60-40 vol. \%). Physio-chemical characterizations and SARA fractionation method of analysis were carried out to identify the behavior of the crude oil before processing as shown in Tables I and Table II.

\section{B. Cocamide DEA}

The non-ionic surfactant Cocamide Diethanolamine "Cocamide DEA" was used in this study as natural emulsifying agent at varying doses $(0.2,0.5,1$, and 1.5$)$ vol. $\%$ (based on the total of the emulsion) to investigate the stability and the rheology properties of Malaysia crude oil emulsions.

\section{ARA Method of Analysis}

Asphaltenes, Aromatic, Resin, and Saturated "SARA" 
method of analysis was performed to identify the chemical characterization of the crude oil samples. The fractions that considered in this study include those in the categories of Asphaltenes, Aromatic, Resin, and Saturated compounds. The analytical design of the standardized ASTM "American Society for Testing and Materials" method, ASTM D2007, that employs an open-column liquid chromatography [11], [12] was used to separate the crude oil into two major fractions; Asphaltenes and Maltenes "Aromatic, Resin, and Saturated" compounds.

\section{Emulsion Preparation and Testing}

24 samples of water-in-crude oil "w/o" emulsion samples at different fractions by volume of water and oil phases (50-50, and 20-80) vol.\% were prepared and characterized with respect to hydrocarbon chain distribution, surfactant type and concentration, as well as viscosity dependence. In graduated beakers, $300 \mathrm{~mL}$ of w/o emulsion was prepared by the "agent-in oil" method through dissolving the Cocamide DEA (stabilizing gent) in the crude oil sample (continues phase) then the sample was sheared vigorously for 6 minutes. After that, water (dispersed phase) was added gradually and slowly to the mixing phase (oil and surfactant) then agitated for another 4 minutes. The preparation process was achieved using a standard three blade propeller at a different rotational speeds ( from 1500 to 1800 ) $\mathrm{rpm}$ at $30{ }^{\circ} \mathrm{C}$ for 10 minutes. The prepared emulsions were examined by filter paper as well as by test tube methods to identify the type of emulsion whether a water-in-oil or an oil-in-water.

\section{E. Stability Test}

The gravity separation test was performed to measure the stability of prepared emulsions by observing the amount of water separated. w/o emulsion was placed in graded cylinder and left for settling by gravity forces for one week. The percentage of water separated "W\%" was calculated as separation efficiency as illustrated in the equation:

$$
W \%=\frac{(\text { Vol. of separated water layer, } \mathrm{mL})}{(\text { Original amount of water, } \mathrm{mL})} \times 100
$$

\section{F. Apparent Dynamic Viscosity}

The dynamic viscosity of prepared emulsions was determined by Brokfeild Rotational Digital Viscometer Model LV/DV-III with UL adapter and spindle \# 31. The Viscometer was connected with a water bath thermostat. Viscosity measurements were performed with different shear rate $(17,34,51$, and 85$) 1 / \mathrm{s}$ at different temperatures $(30,50$, 70 , and 90$) \circ \mathrm{C}$.

\section{RESUlTS AND DisCUSSION}

\section{A. Crude Oil Properties}

Depend on the Phyio-chemical properties and SARA method of analysis, it was found that sample A behaves as heavy crude oil whereas sample B behaves as medium crude oil, as shown in Table I and Table II.

\section{B. Effects of Emulsifier Concentration and Water Volume Fraction on the Emulsion Stability}

The effect of Cocamide DEA concentration on the stability of Malaysian crude oil samples is presented in Fig. 1, and Fig. 2. The purpose of using DEA as a stabilizer for the advantage of the recovery in the refinery compared to other agents is much easier. The dosages of Cocamide DEA were varied at $(0.2,0.5,1$, and 1.5$)$ vol. $\%$ for screening purpose. Stability was evaluated by the percentage of water separated from the emulsion which was measured from the cylinder where readings were collected after 1,3 , and 6 hours for the first day. After, the readings were collected each 24 hours over period for one week. The main task of this screening process was to find the best emulsion formulation in term of emulsifier concentration, since concentration is very significant from an economic point of view. Generally, in every experimental emulsification study, stability test is required to find out the best and reliable emulsion at lower cost [13].

Fig. 1 (a) and Fig. 1 (b) showed the stability progress of the crude oil emulsion contains (50 vol. \%) of water for heavy and blended crude oil samples, respectively. For the heavy crude oil emulsion (Fig. 1 (a)), it can be observed that the water coalescence occurred after 1 hour of settling time and the separation percentages reached to (60-66)\%, respectively, during the first day of settling time. After 24 hours, the separation percentages were increased up (71- 83) \%, respectively. Moreover, it can be noted that increasing the concentration of the emulsifier (from 0.2 to 1.5 ) vol. \% could reduce the coalescence of water droplets and therefore enhance the stability.

Compare to the w/o emulsion of the blended crude oil sample (Fig. 1 (b)), it was found that using (0.2 vol.\%) of DEA was insufficient in stabilizing the emulsion due to immediate coalescence that reached to $76 \%$ after 24 hours of settling time. However, the concentration of $(0.5,1$, and 1.5) vol. $\%$ were significant in stabilizing the emulsion where there was no separation occurred at all during the 6 hours of settling time. Even though the coalescence occurred after 6 hours, but it was about $(30,8.6$, and 5.4) \%, respectively.

As a result, the gravity separation test for (50-50) vol. $\%$ of w/o emulsion revealed that DEA concentration at (1.5 vol. \%) could enhance the stability of the blended crude oil emulsion. Conversely, Cocamide DEA at this concentration is insufficient in stabilizing the w/o emulsion of the heavy crude oil sample. Hence, the DEA concentration should be increased higher than $(1.5 \mathrm{vol} . \%)$ in order to produce an emulsion with better stability.

TABLE I: PHYSIO-CHEMICAL PROPERTIES OF THE CRUDE OIL SAMPLES
\begin{tabular}{|l|l|l|l|}
\hline Crude Oil Samples & $\begin{array}{l}\text { Density } \\
\left(\mathrm{g} \cdot \mathrm{cm}^{-3}\right)\end{array}$ & Viscosity (m.Pas) & $\begin{array}{l}\text { API } \\
\text { Gravity }\end{array}$ \\
\hline A & 0.947 & 298.7 & 17.13 \\
\hline B & 0.893 & 19.1 & 26.12 \\
\hline
\end{tabular}

TABLE II: SARA FRACTIONATION OF THE CRUDE OIL SAMPLES

\begin{tabular}{|c|c|c|c|c|}
\hline Crude oil sample & $\begin{array}{c}\text { Asphalten } \\
(w t \%)\end{array}$ & $\begin{array}{c}\text { Saturated } \\
(w t \%)\end{array}$ & $\begin{array}{c}\text { Aromatic } \\
(w t \%)\end{array}$ & $\begin{array}{c}\text { Resines } \\
(w t \%)\end{array}$ \\
\hline A & 12.2 & 48.7 & 34.6 & 4.5 \\
\hline B & 7.6 & 61.4 & 27.2 & 3.8 \\
\hline
\end{tabular}



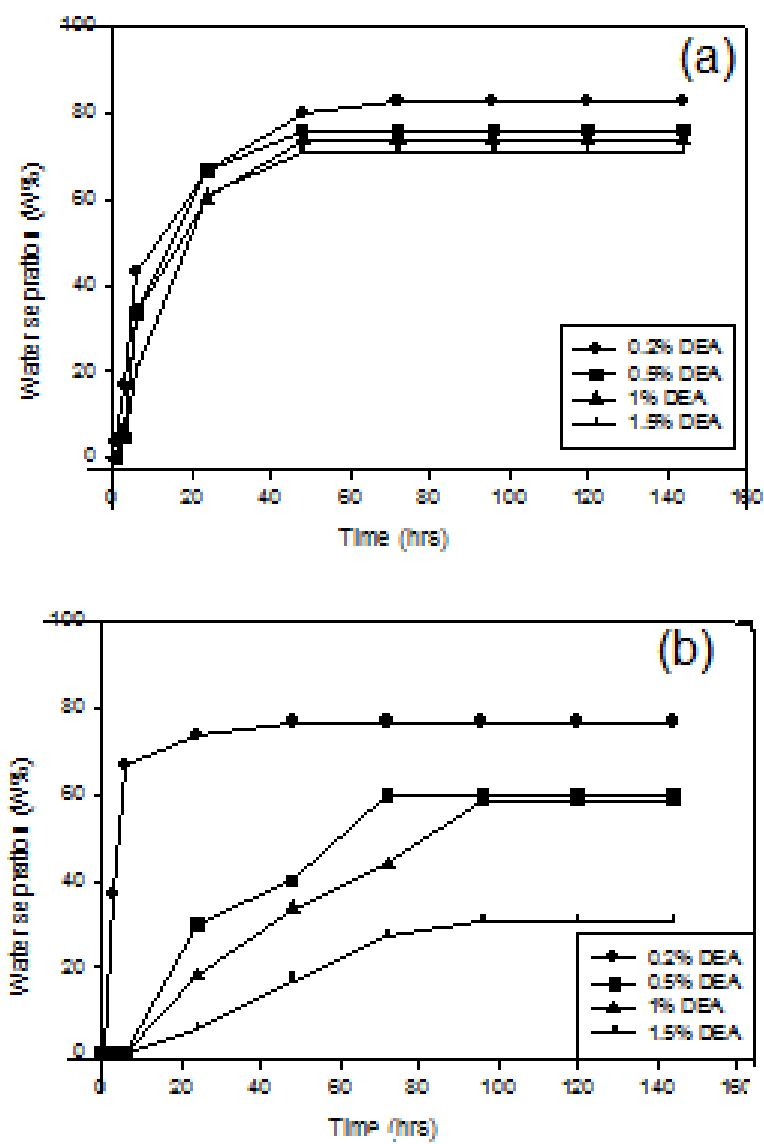

Fig. 1. Effect of DEA concentrations on (50-50) vol.\% w/o emulsion of: a) Heavy crude oil, and b) Blended crude oil.

Fig. 2 (a) and Fig. 2 (b) presented the stability of the heavy and the blended crude emulsions contain (20 vol. $\%$ ) of water and stabilized by Cocamide DEA. In Fig. 2 (a), it can be seen that using the DEA at concentrations of (1, and 1.5) vol.\% were significant in stabilizing the heavy crude oil emulsion for 50 hours as there was no water separated at all. Even though there was a coalescence occurred after the 50 hours, but it considered trivial and the percentage of water separated were $(15.2$, and 16.9$) \%$, respectively. In contrast, lowering the concentration to $(0.2$, and 0.5$)$ vol. $\%$ were insufficient in stabilizing the w/o emulsion as the coalescence occurred after 3 to 6 hours of settling time and separations were between (45.9, and 28.4) \%, respectively.

Compare with the separation progress of the blended crude oil emulsion (Fig. 2 (b)), it was found that using (1.5 vol.\%) of DEA was sufficient to produce stable emulsion where there was no separation occurred during the first 24 hours. After, coalescence was occurred to give $16.8 \%$. However, using the concentrations of $(0.2,0.5$, and 1$)$ vol. $\%$ of DEA the coalescence occurred and the percentage of water separation was $(36.7 \%, 31.8 \%$, and $28.6 \%)$, respectively.

According to the gravity separation test for (20-80 vol. \%) of w/o emulsion, the DEA concentration at (1, and 1.5) vol. \% gaves better stability for heavy crude oil emulsion up to 50 hours. Whereas, for the blended crude oil emulsion, Cocamide DEA concentration at (1.5 vol. \%) was sufficient in stabilizing the emulsion and the stability could be increased if the DEA concentration increased above (1.5 vol.\%) in order to produce high stable emulsion.
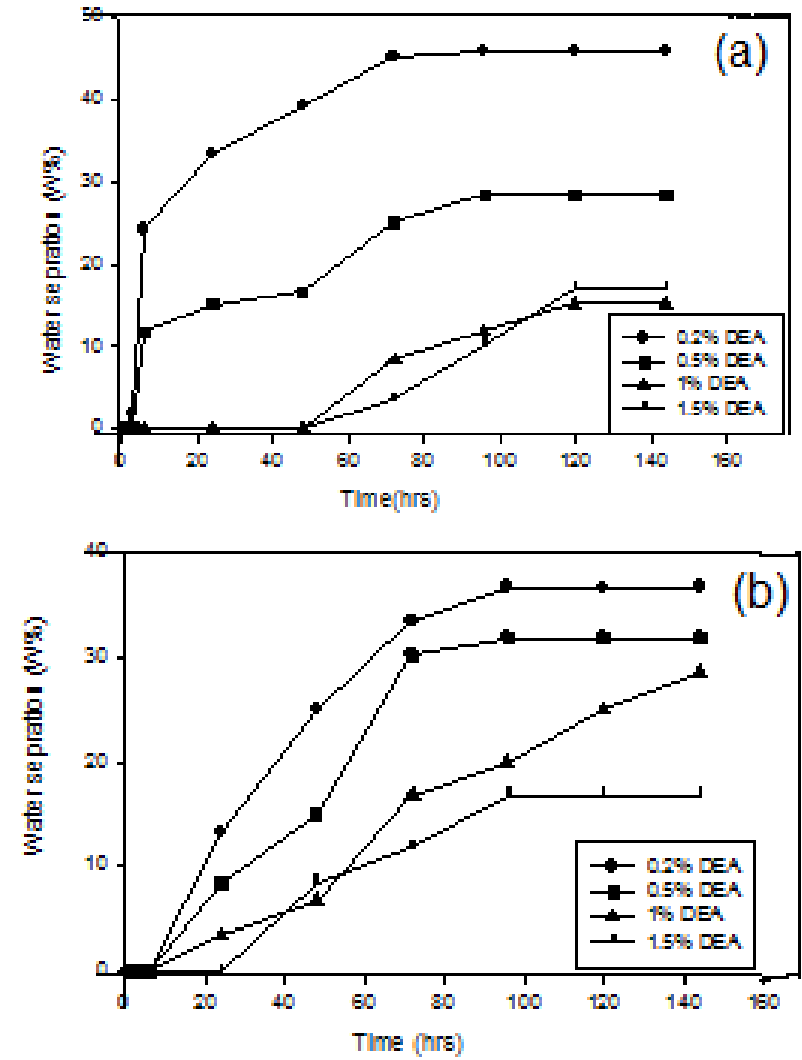

Fig. 2. Effect of DEA concentrations on (20-80) vol.\% w/o emulsion of: a) Heavy crude oil, and b) Blended crude oil

It can be concluded that the stability of the emulsion enhanced when the surfactant concentration increased. The reson behind that is because the emulsion unstable thermodynamically due to the high free energy of the multiphase system, therefore the presence of surfactant will increase the molecules adsorbed at the water/oil interface that can result in intermolecular interactions, which will work against any strain on the interface (Gibbs-Marangoni Effect), and providing an electrostatic and steric barrier to coalescence mechanism among the water droplets due to their non-ionic nature and stabilizing the system[14], [15]. Regarding to the effect of water volume fractions, it was found that the most stable emulsion was noted at a water volume fraction of $(20 \%)$ where the Cocamide DEA showed better results with all concentrations used in stabilizing the w/o emulsion at room temperature. Compared to the higher volume fractions of water $(50 \%)$, emulsion was stable for a few hours before the water coalescence as a separate layer down the emulsion which considered as a medium or loose emulsion. Increase the coalescence rate with increase the water volume fraction is due to increase the entropy between the water droplets for effective collision [14]. Thus, it is clear evidence that reducing the volume fraction of water and increasing the concentration of Cocamide DEA will give a better stability for w/o emulsion at room temperature.

\section{Effects of Water Volume Fraction and Shear Rate on the Emulsion Stability}

Several factors namely; temperature, rotation speed, shear stress, and shear rate was considered to investigate the effects of the water content and the shear rate on the viscosity behavior and further on the stability of w/o emulsions to provide complete information about Non-Newtonian or 
Newtonian behavior of the system. As stated in [15], stability of emulsions relates to their bulk phase elastic behavior and the viscoelastic fluids are a common form of the non-Newtonian fluid. Typically, fluids that have a high molecular weight are usually having this behavior [16]. In fact, each emulsion investigated has a viscosity more than the viscosity of the oil (continuous phase).

Fig. 3 (a) and Fig. 3 (b) demonstrated the effects of the water content on the viscosity behavior of w/o emulsions for the heavy and the blended crude oil samples that stabilized with $(1.5 \mathrm{vol} . \%)$ of DEA at different rotational speeds and temperatures. For the heavy crude oil emulsion (Fig. 3 (a)), the viscosity of emulsion contains $(50 \mathrm{vol} . \%)$ of water was (264) $\mathrm{m} \cdot \mathrm{Pas}$ at $50 \mathrm{rpm}$ and $50{ }^{\circ} \mathrm{C}$. However, when the water content reduced to $(20 \mathrm{vol} . \%)$, the viscosity was reduced to (227.2) $\mathrm{m} \cdot \mathrm{Pas}$ at the same testing conditions. Similar behavior was observed with the emulsion of the blended crude oil sample (Fig. 3 (b)). It was found that reducing the water content (from 50 to 20) vol.\%, emulsion viscosity was reduced (from197.3 to 65.3) $\mathrm{m} \cdot \mathrm{Pas}$, respectively, at $50 \mathrm{rpm}$ and $50{ }^{\circ} \mathrm{C}$.

The reason behind increase the viscosity with increase the water volume fraction (dispersed phase) which resulted in faster coalescence is due to the presence of the hydrogen bond which means the inter droplet distance is higher, therefore the droplets stay close to each other and thus the effect of hydrodynamic forces increased as well as the deformation is increased [6], [17].
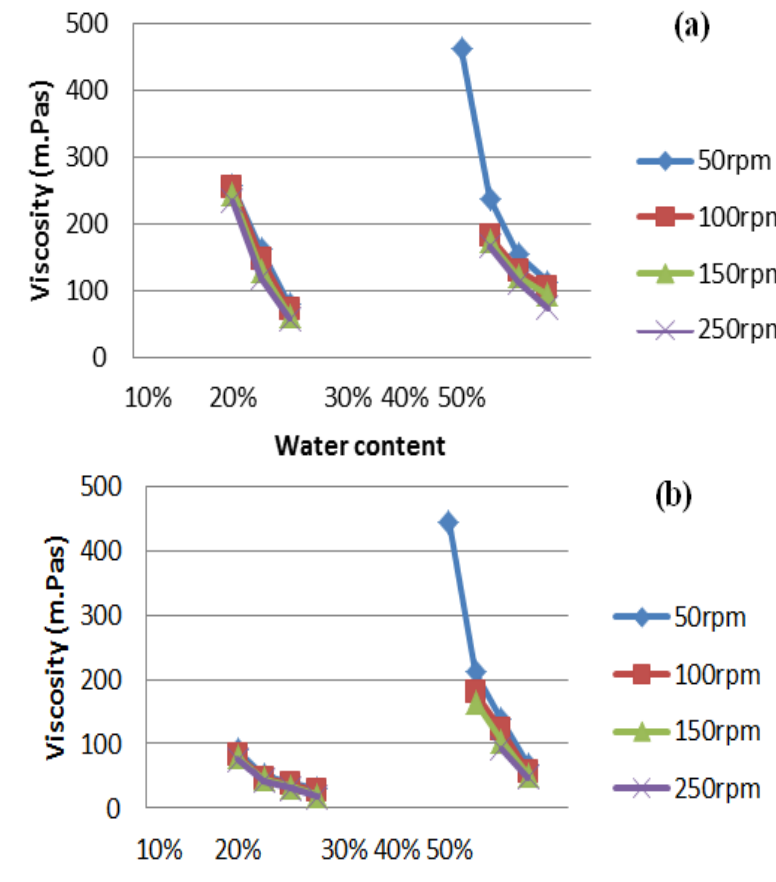

Water content

Fig. 3. Effect of water content on viscosity of w/o emulsion stabilized with DEA $(1.5 \mathrm{Vol} . \%)$ at different temperature and rpm: a) Heavy crude oil, and b) Blended crude oil.

\section{Effects of Shear Rate and Shear Stress on the Viscosity Behavior and Stability of the Emulsions}

To investigate the flow behavior of the w/o emulsion, the relation between shear rate and shear stress was plotted as presented in Fig. 4 and Fig. 5. Fig. 4 (a) and Fig. 4 (b) showed the effects of the shear rate and the shear stress on heavy crude oil emulsion stabilized by $(1.5$ vol. $\%)$ of the DEA at different volume fractions of water (50, and 20) vol.\% and different temperatures (from 30 to 90 ) ${ }^{\circ} \mathrm{C}$. It can be observed that the shear stress increased gradually and significantly with the shear rate. Thus, these emulsions having a Non-Newtonian behavior. Similar behavior was noticed with the emulsion of blended crude oil stabilized by (1.5 vol.\%) of the DEA at different volume fractions of water (50, and 20) vol. $\%$ and different temperatures (from 30 to 90 ) ${ }^{\circ} \mathrm{C}$, as shown in Fig. 5 (a) and Fig. 5 (b). Accordingly, all emulsions are characterized the Non-Newtonian behavior.
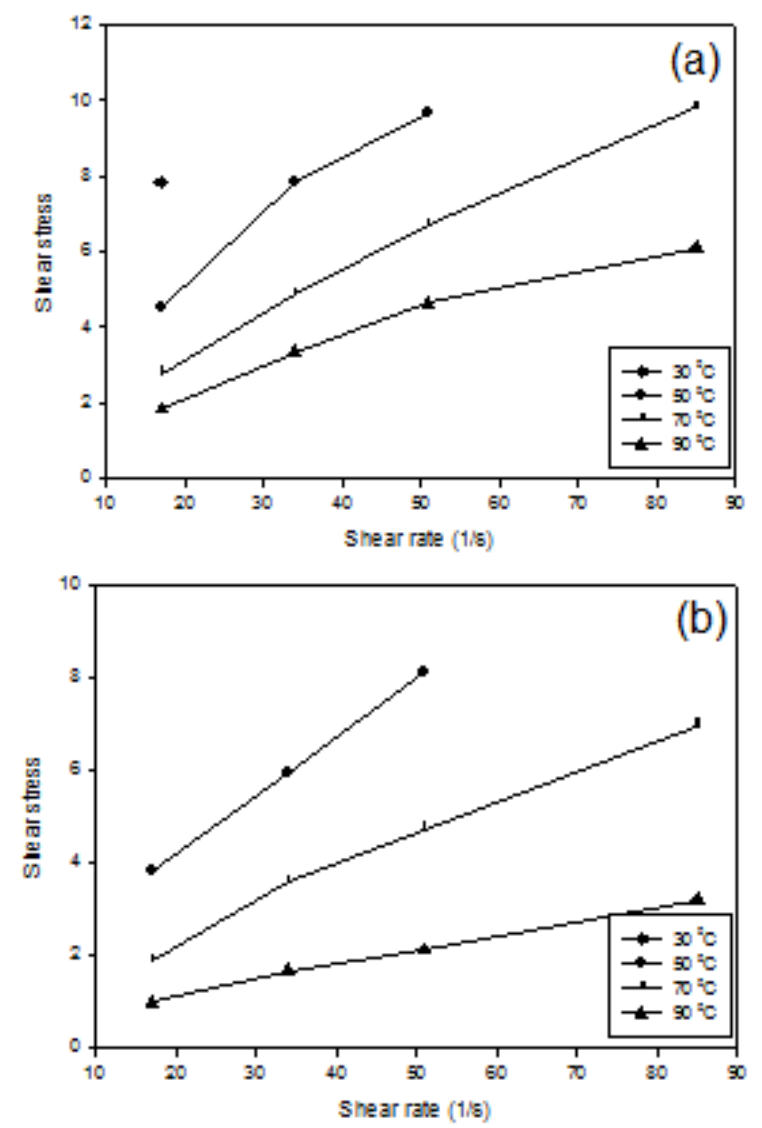

Fig. 4. Effects of shear rate and shear stress on viscosity of: a) (50-50) vol.\% of the heavy crude oil emulsion, b) (20-80) vol.\% of the heavy crude oil emulsion stabilized with $(1.5 \mathrm{vol} . \%)$ of DEA at different temperatures.

The effects of the shear rate data on viscosity and further on the stability of (50-50, and 20-80) vol.\% w/o emulsions for heavy and blended crude oil samples are plotted in Fig. 6 and Fig. 7, respectively. It is clear that over a range of shear rate (from 17 to 85 ) 1/s, the apparent dynamic viscosity was a function of the shear rate as it decreased with increased the temperature (from 30 to 90 ) ${ }^{\circ} \mathrm{C}$. In another word, all emulsions were found to follow shear thinning behavior "pseudo-plastic".

Moreover, it can be observed that emulsion with the lowest water volume fraction of (20\%) (Fig. 6 (b), and Fig. 7 (b)) exhibited the lowest viscosity values and characterizing less elastic behavior. Compare these results with the results of $(50 \%)$ water volume fraction, it was found that emulsion with (50 vol.\%) of water characterizing high elastic behavior that needs a higher shear rate, as presented in Fig. 6 (a), and Fig. 7 (a). These results were due to increase the number of the hydrogen bonds that leads to increase the hydrodynamic forces and hence the viscosity [3], [17]. Thus, it needs a high shear rate to start the deformation. 

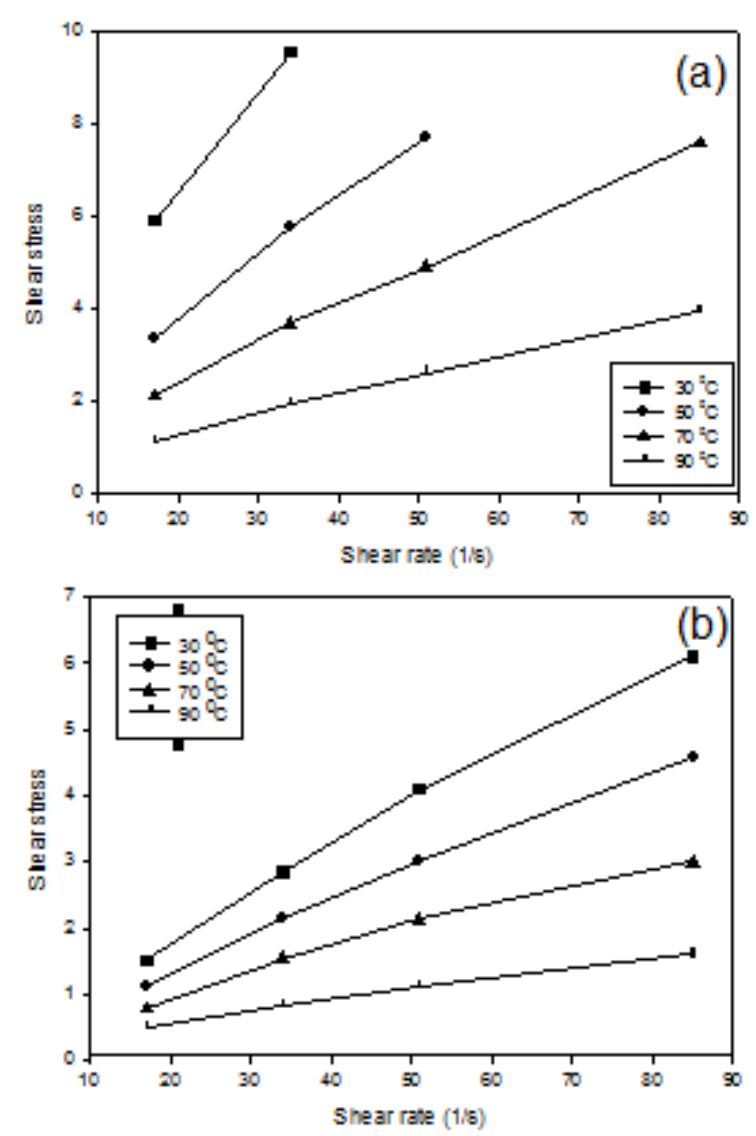

Fig. 5. Effects of shear rate and shear stress on viscosity of: a) (50-50) vol.\% of the blended crude oil emulsion, and b) (20-80) vol.\% of the blended crude oil emulsion stabilized with $(1.5 \mathrm{vol} . \%)$ of DEA at different
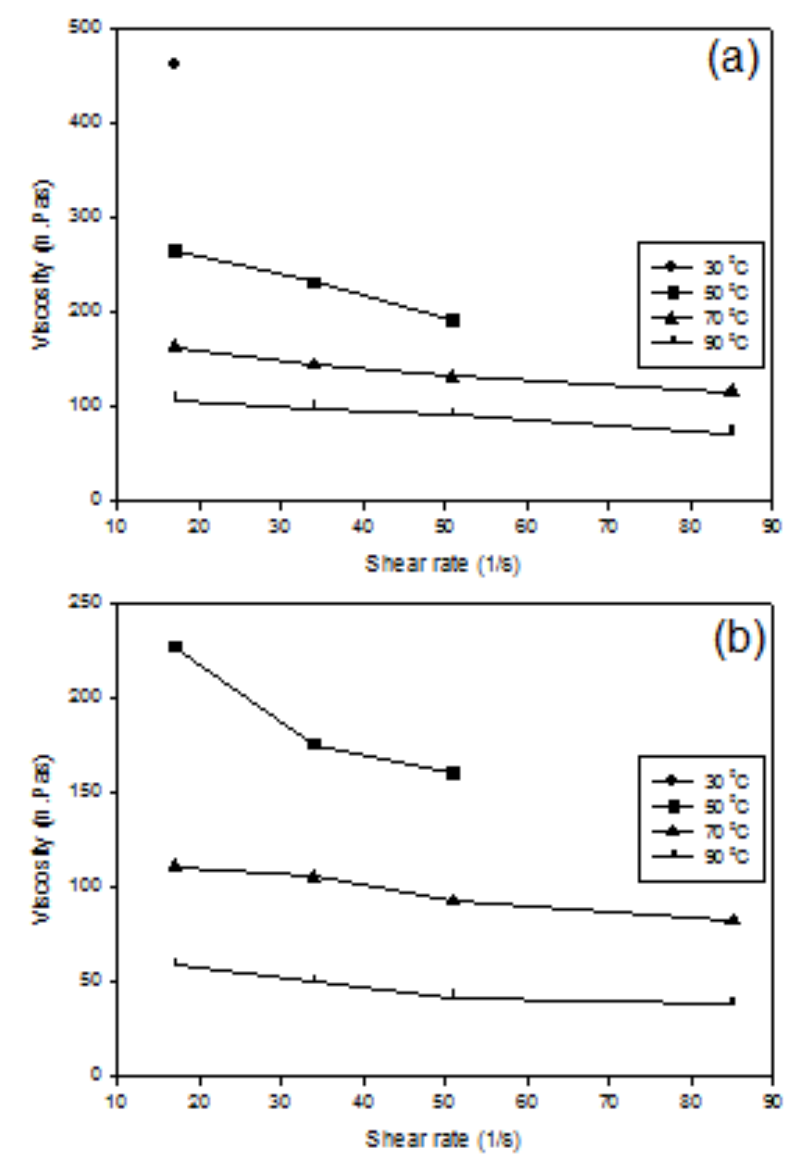

Fig. 6. Effect of shear rate on viscosity of: a) Heavy oil emulsion with (50 vol.\%) of water, b) Heavy oil emulsion with (20 vol.\%) of water stabilized by $(1.5$ vol. $\%)$ of DEA at different temperatures.
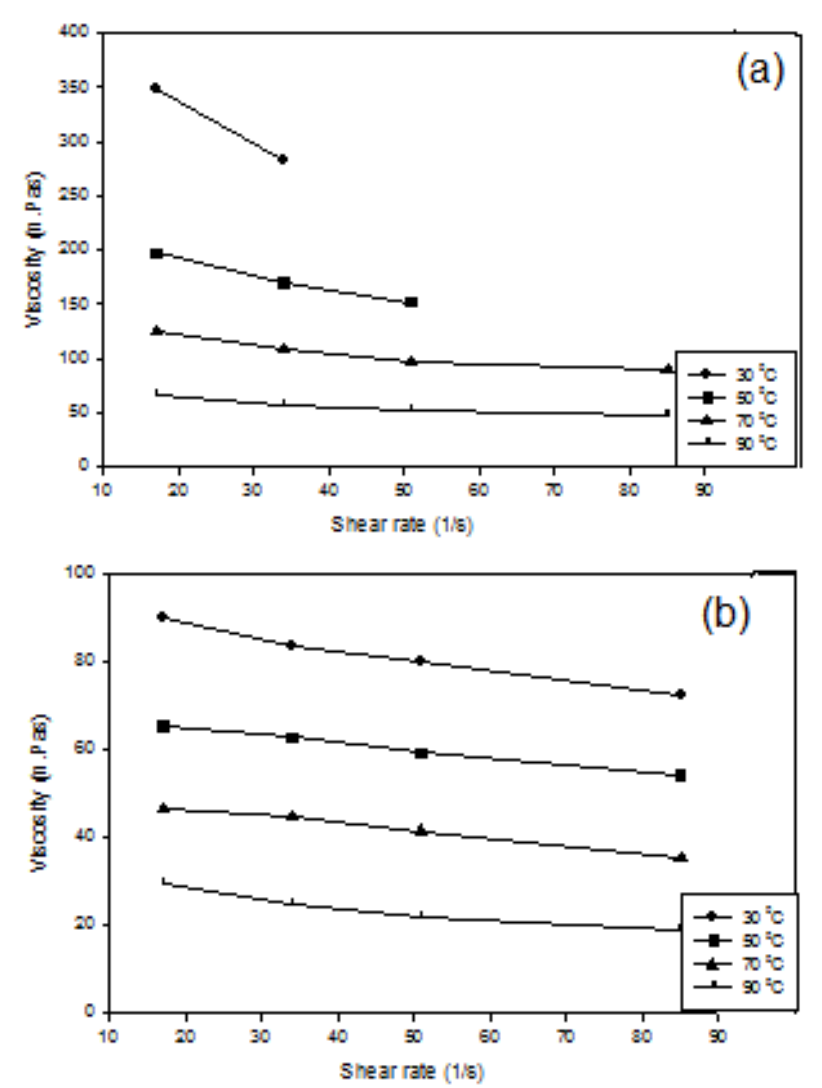

Fig. 7. Effect of shear rate on viscosity of: a) Blended crude oil emulsion with (50 vol. \%) of water, and b) Blended crude oil emulsion with (20 vol.\%)

of water stabilized by (1.5 vol.\%) of DEA at different temperatures.

\section{CONCLUSION}

The present study demonstrated the kinetic stability and the rheology of water-in-crude oil emulsion stabilized by Cocamide DEA at different water volume fractions using two types of Malaysian crude oil samples. Several factors namely: surfactant concentration, water content, shear rate, shear stress, temperature, and rotational speed were investigated. The findings of this study were highlighted as; high concentration of $(1.5 \mathrm{vol} \%)$ Cocamide DEA was a good natural surfactant that has the ability to stabilize the w/o emulsion kinetically and thermodynamically for both crude oil samples at room temperature. Low water volume fraction was effective in stabilizing the w/o emulsion through reducing the viscosity that resulted inhibition in the coalescence process. All w/o emulsions investigated were found to follow Non-Newtonian shear thinning (pseudo-plastic) behavior.

\section{REFERENCES}

[1] S. J. Joblom, Encyclopedic Hand Book Of Emulsion Technology, New York: Marcel Dekker, 2001.

[2] J. Bibette, F. L. Calderon, V. Schmitte, and P. Pouline, "Introduction in emulsion science-basic principles," Springers, 2001.

[3] L. K. Sunil, "Crude Oil Emulsions," in Petroleum Engineering Handbook: General Engineering, W. L. Larry and R. F. John ed. Texas, U.S., 2006, vol. 1, ch. 12.

[4] J. David and M. Clements, Food Emulsions: Principles, Practices, and Techniques, 2nd ed, vol. 2, pp. 269, 2005.

[5] S. N. Ashrafizadeh and M. Kamran, "Emulsification of heavy crude oil in water for pipeline transportation," Journal of Petroleum Science and Engineering, vol. 71, pp. 205-211, 2012.

[6] W. H. Shadi, T. G. Mamdouh, and E. Nabil, "Heavy crude oil viscosity reduction and rheology for pipeline transportation," J. Fuel, pp. 1095-1100, vol. 89, 2010. 
[7] L. Mingyuan, A. A. Christy, and J. Sjoblom, Emulsion-A Fundamental and Practical Approach, J. Sjoblom, ed., NATO ASI Ser, Kluwer Academic Publisher, 1992, pp. 363-157.

[8] H. N. Abdurhman, A. Suliman, and M. H. Mohmmoud, "Stabilization mechanisms of water-in-crude oil emulsions," Journal of Applied Sciences, vol.8, pp. 1571-1575, 2008.

[9] P. Sherman, Encyclopedia of Emulsion Technology, P. Beacher ed., New York: Marcel Dekker, 1983.

[10] M. T. Ghannam and N. Esmail, "Rheological properties of carboxymethyl cellulose," J. Appl. Poly. Sci., vol. 64, pp. 289-301, 1998,

[11] D. Vazquez and G. A. Mansoor, "Identification and measurement of petroleum precipitates," Journal of Petroleum Science and Engineering, vol. 26, pp. 49-55, 2000.

[12] V. C. Laura and F. Vazquez, "Fractionation and characterization of Mexican crude oil," Journal of Energy and Fuels, vol. 23, pp.1603-1699, 2000.

[13] N. N. Zaki, M. E. A. Raouf, and A. A. A. Azim, "Propylene oxide-ethylene oxide block copolymers as demulsifiers for water-in-oil emulsions II. effect of temperature, salinity, $\mathrm{pH}$-value, and solvents on the demulsification efficiency," J. Chemical Monthly Austria, vol.127, pp.1239-1245, 1996.

[14] N. N. Zaki, "Surfactant stabilized crude oil-in-water emulsions for pipeline transportation of viscous crude oils," J. Colloids Surfaces A: Physicochem. Eng. Aspects, vol. 125, pp. 9-25, 1997.

[15] C. M. F. Dílson, B. V. S. Joao, S. S. Luciana, and F. L. Elizabete, "Aging of water-in-crude oil emulsions: Effect on rheological parameters," J. Colloids and Surfaces A: Physicochem. Eng. Aspects, vol. 405, pp.73-78, 2012.

[16] G. B. Donald. (2012 Augast). Flow behavior of viscoelastic fluids. Chemical Engineering, Virginia Polytechnic Institute and State University, Blacksburg, Virginia. [Online]. Available: http://www.accessscience.com/abstract.

[17] A. N. Ilia and H. N. Abdurahman, "Affect of viscosity and droplet diameter on w/o emulsion," J. World Academy of Science, Engineering, and Technology, vol. 38, pp.691-694, 2010

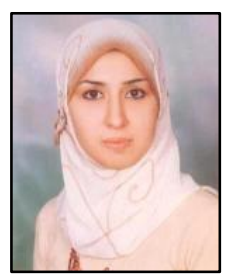

Rasha M. Abd was born in Iraq on July 19, 1982 Currently, she is a Ph.D. candidate in chemical engineering program at Faculty of Chemical Engineering and Natural Resources, University Malaysia Pahang, Pahang, Malaysia. The master degree was in biotechnology engineering earned from Faculty of Engineering, International Islamic University Malaysia, Selangor Darul Ehsan, Malaysia, 2011. The bachelor degree was in chemistry, Faculty of Science, Al-Mustansryia University, Baghdad, Iraq, 2004.

She was a part-time research assistant for research endowment fund entitled "Optimization of Enzyme Immobilization on Carbon Nanotubes" at the Research and Management Center, International Islamic University Malaysia (IIUM), Selangor, Malaysia. She published 4 journal papers, 4 conference papers ( Ma`an F. Alkhatib, Md. Zahangir Alam, and Rasha Mohammed, "Statistical Modelling of Cellulase Enzyme Immobilisation on Functionalized Multi-Walled Carbon Nanotubes for Empty Fruit Bunches Degredation", Australian Journal of Basic and Applied Sciences, vol. 6, pp.30-38, 2012,. And Ma`an F. Alkhatib, Rasha Mohammed, Md. Zahangir Alam, and Hamzah Mohd M. Saleh, "Enzymatic Hydrolysis of Oil Palm Empty Fruit Bunch using Immobilized Cellulase Enzyme", African journal of Biotechnology, vol. 10, pp.18811-18815, 2011). Current research interest is in optimization, characterization, and microwave demulsification of crude oil emulsions.
Mrs. Rasha awarded 1 Gold, 2 Silver, and 1 Bronze Medals in exhibitions of university and national levels.

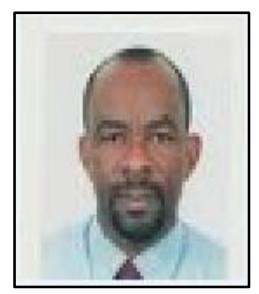

Abdurahman H. Nour Was born in Sudan in 1970. He has Ph.D., Faculty of Chemical and Natural Resources Engineering, Universit Technologi Malaysia (UTM), 2006. M. Sc Engineering in Petroleum Engineering, Department of Petroleum Engineerin, Aalborg University of Engineering (Aalborg U) Denmark, 2003. M. Sc. Engineering in Chemical and Environmental Engineering Department of Chemical and Environmental Engineering Universiti Putra Malaysia, UPM, 2000. B.Sc. Engineering in Petroleum Engineering, Department of Petroleum Engineering, Alfateh University,1994. Senior lecturer, Faculty of Chemica and Natural Resources Engineering, Universiti Malaysia Pahang (UMP), November 18, 2007 to 2011. Visiting Lecturer, Universiti Malaysia Pahang (UMP), 2007 to November 18, 2007. Teaching assistant (TA), Faculty of Chemical and Natural Resources Engineering, Universiti Technologi Malaysia (UTM), 2004-2006. Teaching assistant (TA), Faculty of Chemical Engineering, Aalborg University, Denmark, 2001-2002. He has many publication such as: Abdurahman H. Nour; Y. M. Rosli; N. H. Azhari, 2011 Development of a membrane anaerobic system (MAS) for palm oil mill effluent (POME) treatment. Journal of Desalination, 266, 208-212. S.Nuurul Huda and Abdurahman H. Nour 2011. Microwave Separation of Water-in-Crude Oil Emulsions. International Journal of Chemical and Environmental Engineering, Volume 2, (1); 69-75. And Abdurahman H. Nour; R. Sothilakshmi; Azhary H. Nour, 2010. Microwave Heating and Separation of Water-in-Crude Oil Emulsions: An Experimental Study. International Journal of Chemical Technology. 2(1): 1-11. Research interest eparation of Crude Oil Emulsion: Emulsification, Demulsification, and Characterization of Crude Oil Emulsions; Modeling and Simulation of Reservoir Production; Well Testing; Waste water Treatment Plant; CFD Modeling for drag reduction in pipeline; Extraction of essential oil using microwave - assisted with Hydrodistillation compared to Conventional Hydrodistillation Methods; Composite Process. Dr. Abdurhman won 6 gold, 12 silver, 3 bronze medale in inteational ehibitions

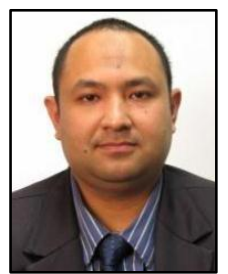

Ahmad Z. Sulaiman holds a B.Eng (Hons) and M.Eng (Chemical Engineering) degree from University of Technology, Malaysia, and a Ph.D. in Biochemical Engineering from Massey University, Palmerston North, New Zealand. Currently, he works as a senior lecture of biochemical engineering in the Faculty of Chemical and Natural Resources Engineering, Universiti Malaysia Pahang, Malaysia He is a Registered Engineer under Board of Engineers Malaysia (BEM), Graduate Member of the Institution of Professional Engineers New Zealand (GIPENZ), Associate Member of the Institution of Chemical Engineers (AIChemE), UK., and Member of New Zealand Microbiology Society. His work addresses many aspects of biochemical and chemical engineering, applied biotechnology, and environmental technology. His research areas include bioreactor design, microbial fermentations, enzyme technology, separation technology, herbs extraction (solvents and enzymatic extraction), sonobioreactors technology, ultrasound and transport phenomena. 